\section{Traços polissêmicos do verbo calcular}

\author{
Polysemic features of the verb \\ to calculate
}

Letícia DE ALMEIDA Barbosa (UFMS) leticiaalmeidabarboza@gmail.com

Solange DE CARVALHO Fortilli (UFMS) fortilli@yahoo.com.br

Recebido em: 30 de jan. de 2018. Aceito em: 30 de maio de 2018.
DE ALMEIDA, Leticia Barbosa; DE CARVALHO, Solange Fortilli. Traços polissêmicos do verbo calcular. Entrepalavras, Fortaleza, v. 8, n. 2, p. 401-418, maio/ago. 2018.

Resumo: Este trabalho tem como objetivo discutir aspectos semânticos do verbo calcular que, em contexto prototípico, significa determinar valor ou grandeza numérica por meio de raciocínio matemático. Em situações reais de comunicação, nota-se a existência de empregos diversos para calcular, ora expressando o valor ou a quantidade de algo concreto, ora quantificando algo abstrato ou ainda funcionando como um parêntese ou informação extra relacionada à postura do falante sobre o que é dito. Esse comportamento revela modificações no significado do verbo, que, de predicado que seleciona dois argumentos concretos, vem apresentando reforço nos traços ligados à subjetividade e à intersubjetividade, estando os processos polissêmicos ligados a essa mudança. Como fundamentação teórica, a pesquisa apoiou-se em estudos como os de Sweetser (1990), Heine et al. (1991), Hopper e Traugott (1993), Neves (2000) e Martelotta (2010), que tratam de mudanças semânticas no âmbito da Gramaticalização. Mais especificamente, tomou-se por base Casseb-Galvão (2000) e Fortilli (2015), por tratarem de verbos que passam por alterações semelhantes. Para o levantamento e análise de dados, 
V. $8(2)$

401-418 mai/ago 2018

foram selecionados casos encontrados entre os séculos XIX, XX e XXI no Corpus do Português. Os resultados apontam para uma maior disseminação dos usos do verbo calcular em configuração parentética, o que se justifica pelo processo de abstração de seu significado, pois, quando parentetizado, o verbo deixa de referenciar traços semânticos específicos de um processo mental e evidencia traços de incerteza do falante diante do que está sendo afirmado.

Palavras-chave: Polissemia. Verbos cognitivos. Gramaticalização.

Abstract: The present work aims to present the semantic features of the verb "to calculate" that, in prototypical context, has the meaning of determinate value or numerical greatness by mathematical reasoning. In real situation of communication, we observe that there's a significant amount of examples to calculate, sometimes expressing the quantity of something concrete, sometimes quantifying something abstract, or even working as a parenthesis or extra information related to the speaker's posture on what is said. This behavior reveals the changes of the verb meaning. So, the predicate that selects two concrete arguments, would be turning into a subjectivity and intersubjectivity marker. As a theoretical support, an analysis was based on studies such as Sweetser (1990), Heine et al (1991), Hopper and Traugott (1993), Neves (2000) and Martelotta (2010), which deal with semantic changes in the field of grammaticalization. More specifically, it was taken as base Casseb-Galvão (2000) and Fortilli (2015), for dealing with verbs that pass through similar alterations. For the collection and analysis of data, we selected cases found between the 19th, 20th and $21 \mathrm{~h}$ centuries, in Corpus do Português. The results point to a greater dissemination of the uses of the verb to calculate in parenthetic configuration, which is justified by the process of abstraction of its meaning, since, when parentethized, the verb to calculate does not refer to specific semantic features and starts to show features that express the non-certainty of the speaker before what is being affirmed.

402

Keywords: Polysemy. Cognitive verbs. Grammaticalization.

\section{Introdução}

Ao compreender a polissemia como a existência de vários significados para uma mesma palavra, é possível observar que, no curso desse processo, outros estão relacionados, como a generalização de significados, que proporciona a atuação de determinado elemento em um maior número de contextos. Com base em Lakoff e Johnson (1980; 2002), é possível afirmar que o processo de criação de polissemias é metafórico e vai do concreto ao abstrato, pois itens lexicais que expressam concretude de significado passam a ser utilizados em contextos mais abstratos, em que o sentido inicial não é, necessariamente, recuperado.

Os verbos de cognição, em sentido mais amplo, são aqueles que expressam processos cognitivos relacionados à memória, compreensão, ao conhecimento, à crença, ao raciocínio lógico e ao posicionamento do falante. São verbos como deduzir, pensar, acreditar, supor, reconhecer, admitir, basear, e outros, que vêm apresentando diferentes funcionamentos, dentre os quais se destaca a proeminência 
de seu valor epistêmico. Dentro deste conjunto de verbos, um nos tem chamado a atenção, pelo fato de possuir, primariamente, traços semânticos bastante ligados a um processo cognitivo específico: o verbo calcular.

De acordo com a tradição gramatical, o verbo calcular é um predicador verbal de dois argumentos, como em: $\mathrm{X}$ calcula $\mathrm{Y}$, sendo o argumento externo um ser animado e humano, e o interno (o objeto) algo contável. Como verbo pleno, calcular nucleia esses elementos em torno de si, visto que exprime uma ação desempenhada pelo sujeito da oração (BECHARA, 2014, p. 33).

É possível notar que os usos do verbo ainda se encontram bastante ligados ao seu sentido específico de "computar, fazer cálculos, avaliar, estimar" (MICHAELIS, 2008, p. 148). Abaixo, seguem alguns usos do verbo calcular, com sua estrutura argumental típica:

(1) Depende do arquiteto que vai lançar a arquitetura da obra, aí eu calculo, o desenhista desenha, mas eu calculei não foi sozinho, eu processei metade dos cálculos utilizei o pessoal da computação... (190r:Br:LF:SP) ${ }^{1}$

(2) Eternamente grato a não poucas provas de affeição e condescendencia, deixo os remanescentes, que calculo em 200 contos de réis, à minha amante D. Sofia Dias, devendo esse legado transmitir-se em qualquer tempo á successão legitima ou illegitima, verificada em regra a filiação. (18:Taunay:Entardecer $)^{23}$

Para além do uso típico de quantificador, como nas ocorrências (1) e (2), vem se observando outros funcionamentos para tal predicado, já que calcular tem se apresentado em diferentes contextos, ora delineando o valor ou a importância de algo concreto, como o raciocínio lógico, ora funcionando como um parêntese/informação extra que relativiza a verdade da proposição. Observam-se, também, casos em que aquilo que se calcula não é concreto e, num primeiro momento, não calculável. Por meio desses comportamentos, hipotetiza-se que a polissemia desse verbo promove também outros "ganhos": aqueles de ordem pragmática,

\footnotetext{
${ }^{1}$ Dado de linguagem oral de falante do estado de São Paulo.

2 Dado de linguagem escrita, encontrado no conto "Ao entardecer", de Afonso de Escragnolle Taunay.

${ }^{3}$ A oscilação no formato de referência de cada dado é própria do corpus.
} 
V. $8(2)$

401-418

mai/ago 2018

que contribuem para a subjetivização, compreendida, de maneira geral, como as atitudes relacionadas a crenças, opiniões e julgamentos que o falante faz em relação a determinado conteúdo. Para além da subjetivização, mais ligada ao emissor, o verbo calcular pode também atuar na intersubjetivização, pois evidencia uma imagem que o falante quer passar sobre si ao ouvinte.

Neste sentido, buscou-se elaborar para o verbo em questão um arranjo de usos capaz de mostrar sua multifuncionalidade, pois, além de ser expressivo de um processo cognitivo mais concreto e ligado a entidades contáveis, também se vincula a experiências mentais do falante relativa a coisas não calculáveis. Mais do que isso, esse verbo se alinha também ao posicionamento do falante sobre o conteúdo proposicional, bem como à imagem que deseja que o ouvinte tenha sobre ele (o falante) ao enunciá-lo. A base para tantas questões quanto ao significado de calcular começaria na polissemia.

\section{Aportes teórico-metodológicos}

Esta seção encontra-se organizada da seguinte forma: primeiramente, são apresentadas as bases dos processos polissêmicos e metafóricos que elucidam o fenômeno que vem afetando calcular. Em seguida, são apresentados os materiais e métodos utilizados para o presente estudo.

Processos polissêmicos e metafóricos

De acordo com Matos (2006), que estuda verbos polissêmicos a partir de Cançado (2005) e Lakoff e Johnson (2002), os vários sentidos que certos verbos podem apresentar resultam de processos cognitivos metafóricos, fato relacionado à existência de uma estrutura conceitual básica (concreta), que proporciona a criação de novos significados.

Em estudos recentes, abarcados por uma proposta cognitivofuncional, é forte a ideia de que a estrutura linguística é derivada de processos cognitivos de domínio geral (cf. BYBEE, 2010). Assim, a passagem de conceitos de um domínio cognitivo a outro (por exemplo, a compreensão do tempo a partir do que se sabe sobre espaço), um dos expedientes geradores da polissemia, é um mecanismo humano global, que não se limita à língua, mas tem reflexos nela .

${ }^{4}$ Os estudos de Bybee (2010) estão essencialmente ligados à emergência e consolidação daquilo que é gramatical na língua, o que se entende por Gramaticalização (GR). Ainda 
Votre (2004), que estuda a gramaticalização e, em específico, questões semânticas a ela ligadas, apresenta um princípio de extensão imagética instantânea, em que a metáfora atua de modo decisivo, o que proporciona aos falantes diversas possibilidades discursivas. Os processos metafóricos são baseados em inferências possíveis entre domínios conceituais, os chamados saltos associativos de um domínio para outro. De acordo com Hopper e Traugott (1993), os saltos não são aleatórios, mas motivados por analogia e relações icônicas. No cerne desse fenômeno, está o fato de que a metáfora é um dos mecanismos que permitem ao falante compreender experiências mais abstratas por meio de experiências mais concretas, o que proporciona a utilização de um item metaforizado ou uma construção em um maior número de contextos.

Seguindo os pressupostos de autores como Taylor (1989) e Lakoff e Johnson (1980), a metáfora propicia a conceituação de experiências mais abstratas por meio de experiências mais concretas, já que os conceitos que dominam o pensamento humano influenciam na percepção do mundo. Por meio de um processo cognitivo metafórico, compreendemos um domínio de experiência com base em outro, e mais, o homem pode expressar-se acerca de uma experiência por meio de outra mais conhecida. Lakoff e Johnson (2002) relatam que os sistemas conceptuais humanos se fundam em nossa experiência física e cultural por meio de uma dupla fundação: esquemas imagéticos e categorias de nível básico, dois conceitos que são instaurados em nossas experiências com o mundo.

Existem diferentes metáforas conceptuais ligando domínios diversos, como a relação estabelecida quando se diz "o amor é uma viagem". Ao expressar-se dessa forma, o falante faz uso de uma fonte concreta/plena de significado para caracterizar o amor, que atua em um domínio mais abstrato. Assim, várias expressões metafóricas podem ser relacionadas tanto à viagem, quanto ao amor, como "estar à beira de um precipício" e "beco sem saída". O mesmo ocorre com a metáfora "tempo é dinheiro", cujo mapeamento conceptual surge de um domínio fonte, para um domínio alvo, no sentido de estabelecer relação semântica relacionada à perda, ganho e gasto, ou seja, ações mais concretas, e, portanto, mais propícias a descrever o tempo, que possui um alto

que o fenômeno que investigamos aqui possa ser alinhado, sob alguns aspectos, à GR, o aproveitamento das ideias da autora, esse ponto, caminha mais no sentido de confirmar a estreita relação entre a polissemia e as experiências cognitivas. 
V. $8(2)$

401-418

mai/ago 2018

grau de abstratização. Segundo Taylor (1989), a conceituação do que é abstrato via âmbitos mais atingíveis da experiência humana leva o falante a um maior grau de expressividade.

Relacionando a metáfora conceptual ao objeto analisado neste trabalho, parte-se da ideia de que o sentido lógico-matemático presente em calcular é mais concreto, até porque, em princípio, calculase aquilo que é palpável e, mais do que isso, contável. Há casos em que sentidos ambíguos são desencadeados, pois não se pode afirmar que essa concretude se mantém, quando o que está sob quantificação não é concreto nem contável, como em (3):

(3) ...eu me preocupo com o que eu estou contribuindo com o bem da média ou não - porque eu pego e calculo uma coisa que chegou ao fim... (190r:Br:LF:SP)

Esse aspecto já pode indiciar a polissemia, que pode estar baseada na relação concreto X abstrato, uma das bases da metáfora. Se confirmado esse crescimento de abstração, entende-se porque o verbo tem tido usos como marcador de posicionamento do falante e índice de intersubjetivização.

Para Casseb-Galvão (2000), ao ocorrer o processo de abstração metafórica, o item não perde suas propriedades de origem, pois as duas funções podem co-ocorrer no sistema linguístico, o que permite, novamente, a interpretação de ambiguidade do verbo em análise. Possivelmente, a abstratização é um dos processos que propiciam a polissemia do verbo calcular, juntamente com a generalização de significados. Esses indícios fortalecem a hipótese de que o verbo calcular pode estar passando por um processo de gramaticalização, como consideram Hopper e Traugott (1993), em que a GR se dá não apenas por mudança de categoria, mas também por alterações funcionais. Em Traugott (2012), baseada em Himmelmann (2004), vê-se:

Uma vez que a gramaticalização é um processo pelo qual materiais mais plenos de significado se tornam mais esquemáticos e menos referenciais, informando o destinatário sobre as relações entre os elementos da sentença e sobre a perspectiva do falante sobre o que é dito, pode-se pensar em desenvolvimento de função processual. Essa perspectiva vê a gramaticalização como mudança funcional e privilegia a expansão. (TRAUGOTT, 2012, p. 19, tradução nossa) ${ }^{5}$

5 "Since grammaticalization is essentially a process by wich more contentful, referential material becomes more schematic and non-referential, cueing the Adressee to the 
Mesmo na "gramaticalização clássica", entendida como um processo de mudança em que um item lexical passa a mais gramatical, a metáfora já se mostra importante. Autores como Hopper e Traugott (1993), Heine et al. (1991) e Gonçalves, Lima-Hernandes, e Casseb-Galvão (2007) descrevem este processo considerando-a metáfora como um mecanismo motivador.

Heine et al (1991, p. 48), ao tratar especificamente da abstratização de significados, propõe: "[...] pessoa> objeto > atividade > espaço > tempo > qualidade [...]". Operando nessa trajetória, a metáfora conceptual possibilita que itens de um domínio concreto sejam recrutados para expressarem domínios mais abstratos, fato que desencadeia a GR, fazendo com que itens lexicais se tornem gramaticais e itens gramaticais aumentem ainda mais a sua gramaticalidade. Para Martelotta (2010), a busca por novos rótulos reflete uma tendência cognitiva mais geral de se utilizar termos de domínios concretos para expressar domínios abstratos, veiculando, assim, estratégias interativas no interior do discurso.

Observando alguns usos do verbo calcular, nota-se uma possível mudança semântica, visto que, em alguns contextos, os falantes fazem uso do verbo para expressar suas próprias inferências, percepções e crenças, não fazendo jus aos traços semânticos que envolvem um raciocínio lógico matemático propriamente dito. O uso parentetizado, na ocorrência (4), torna isso mais claro:

(4) Quem é que se quer apaixonar por uma pessoa que não corresponde a esse amor, estando ainda a recomporse de uma separação recente?? Ninguém, (calculo eu)... ninguém gosta de sofrer! (portaldoamor.com.br) ${ }^{6}$

Para o levantamento de dados, foram selecionados casos dos séculos XIX, XX e XXI, no Corpus do Português (DAVIES; FERREIRA, 2006) disponível online em http://www.corpusdoportugues.org/x.asp. Esse corpus é um banco de dados composto por mais de 45 milhões de palavras, apresentadas em milhares de enunciados de diferentes falantes do português brasileiro e europeu. Ele apresenta dados do século XIV ao XXI, disponibilizando ao usuário a comparação da frequência das palavras; sua distribuição; registros de fala, dados jornalísticos e outros.

relationships between elements in a clause and to the Speaker's perspective on what is said, it can be thought of as the development of procedural functions. This view of gammaticalization regards it as functional changes, and privileges expansion" (TRAUGOTT, 2012, p. 19).

${ }^{6}$ Referência do corpus do português, século XXI. 
v. $8(2)$

401-418

mai/ago 2018

Assim, buscou-se identificar os diferentes usos para o verbo calcular, a fim apresentar a polissemia de tal predicado. Desse modo, corroborando as questões pontuadas até aqui, na próxima seção, serão apresentados quatro diferentes usos identificados para o verbo em questão: i. quantificador de entidades concretas, ii. usos ambíguos/ quantificador de "não calculáveis", iii. marcador de atitude epistêmica e iv. marcador de relação intersubjetiva.

\section{Análise de dados}

Tomando como base duas obras lexicográficas: Michaelis (2008) e Ferreira (2002), foram sistematizados os traços semânticos presentes em calcular. São eles: determinar valor, contar, computar, raciocinar, avaliar, visar lucros, planejar, esperar, aceitar como possibilidade real, prever, estimar, imaginar, conjecturar, presumir e supor.

A investigação do processo polissêmico nesse verbo deu-se pela observação da presença e da prevalência de um ou mais de seus traços, capturados em diferentes casos. De verbo pleno, que seleciona dois argumentos, um externo humano e outro interno concreto, calcular tem se mostrado muito presente no eixo epistêmico, quando, via analogia a outros verbos cognitivos, como achar e acreditar, expressa o posicionamento, a postura epistêmica do falante diante da proposição. Neste sentido, percebe-se a menor atuação dos traços semânticos ligados à concretude de significado.

Para elucidar, são apresentadas, em primeiro plano, mais duas ocorrências com sentidos prototípicos de cálculo:

(5) Calculo em milhares os volumes de todos os gêneros e procedências compulsados por mim. (19:Fic:Br:Rio:Momento)

(6) Entra tudo que a União vender, alugar, emprestar, aplicar, até a receita das privatizações? Velloso - Tudo o que for chamado de ativo ou recebível entra nesta história. Calculo R\$ 140 bilhões. Só de privatização, a expectativa é de arrecadar R\$ 68 bilhões. (190r:Br:Intrv:ISP) 
Na ocorrência em (5), nota-se que calculo desenvolve o seu processo inicial, que é o de computar, fazer cálculos, quantificar, pois, ao dizer "calculo em milhares os volumes (...) compulsados por mim...", o falante dá ênfase à quantificação desempenhada por ele. Além disso, os volumes são concretos e contáveis. O mesmo ocorre em (6), pois, ao dizer "Tudo o que for chamado de ativo ou recebível entra nesta história. Calculo R 140 bilhões", o falante recorre a um raciocínio matemático para chegar a tais estimativas, o que fica bastante evidente quando ele reitera dizendo que a expectativa de arrecadamento da privatização é de R\$ 68 bilhões.

Por outro lado, há casos em que calculo evidencia sua polissemia, na medida em que já não é possível definir, com exatidão, se a relação semântica que o falante de fato quer expressar é quantificação. É possível notar que sentidos concretos de calcular não são favorecidos nas ocorrências (7) e (8):

(7) Neste caso - ao contrário do " Ensaio sobre a cegueira " que abre uma grande angular - há uma redução com base nessa interrogação: quem é o outro? Resposta que eu não tenho, mas calculo que a melhor forma de chegarmos a nós próprios é ter de passar pelo outro, pelo conhecimento das pessoas que nos rodeiam. (190r:Pt:Intrv:Jrnl)

(8) O agente irá então procurar negócios que atendam estas características, dentro de um " mercado virtual " que reunirá agentes atuando em nome de outros usuários. "Calculo que este tipo de tecnologia esteja plenamente operacional dentro de alguns anos, certamente em menos de uma década ", afirma Andrew Lippman. (19N:Br:SCat)

Em (7), percebe-se a abstratização do termo em análise, pois fica claro que, ao refletir sobre as formas de um ser humano chegar ao interior de si mesmo, o falante não está calculando, no sentido de que não está experienciando o ato de realizar, no âmbito de sua mente, um cômputo, uma operação numérica.

Em (8), a análise é semelhante, pois o traço mais concreto de quantificação de uma grandeza de natureza numérica não se apresenta. ambas as ocorrências mostram a ampliação das possibilidades contextuais de calcular. 
V. $8(2)$

401-418

mai/ago 2018

As ocorrências (9) e (10) também são ilustrativas da saliência dos traços de sentido mais abstratos do verbo em questão:

(9) Calculo que o simpático Hugo do Holmes Place também esteja contente. (amelhoramigadabarbie.com)

(10) ...amigas que ligam ao dinheiro e ao status, calculo que por aqui não será muito diferente. (anossavida.pt)

O conjunto das ocorrências (7), (8) (9) e (10) permite ver o enfraquecimento dos traços semânticos vinculados à experimentação cognitiva e a vivacidade daqueles relacionados ao eixo modal. De acordo com Sweetser (1990), a polissemia é um expediente que, dentre outros resultados, proporciona o desenvolvimento de significados modais. Especificamente, o verbo calcular tem reforçado seu matiz epistêmico.

No campo da modalização, situam-se noções como as que se relacionam a possibilidade, necessidade, probabilidade e factualidade. Ao se posicionar acerca de um determinado conteúdo, o falante intervém na definição da validade e do valor de seu enunciado (NEVES, 2000, p. 244). Para a autora, a modalidade epistêmica caracteriza-a como o eixo do conhecimento, visto que o falante, ao se posicionar diante da proposição, expressa marcas de crenças, certeza, probabilidade ou improbabilidade quanto ao conteúdo.

Para Neves (2000):

os advérbios modalizadores são capazes de expressar alguma intervenção do falante na definição de validade de seu enunciado: modalizar quanto ao dever, restringir o domínio, definir a atitude e até avaliar a própria formulação linguística (NEVES, 2000, p. 244).

Assim como os advérbios, verbos modais esclarecem como o falante se posiciona diante da proposição. Nas duas últimas ocorrências, calculo mostra-se como um amálgama de ii) e iii): quantificador de entes não contáveis atrelado à marcação de postura epistêmica do falante. É importante notar que o uso parentético tem forma fixa: trata-se do verbo na primeira pessoa do singular no presente do indicativo. Isso ocorre porque, nesse formato, o verbo é capaz de instanciar sinais da atitude do falante diante da proposição, o que parece não ocorrer em outras configurações mórficas do verbo. Caso o verbo se apresente parentetizado em forma diversa da primeira pessoa do singular, seu valor modal epistêmico se esvai. 
A interpretação explicitada anteriormente indica que, de um domínio conceptual concreto, cujas relações semânticas se dão em torno do ato de computar/quantificar, o verbo calcular passa a ser utilizado metaforicamente, por meio de um domínio conceptual mais abstrato, via operações analógicas, migrando para um eixo mais abstrato. Considerando tal comportamento, observamos a relação dessa mudança com sua configuração como partícula independente da sentença. Essa independência sintática consiste em alguns traços, os quais convêm apontar.

A concepção que se assume sobre parentetização é semelhante à de Jubran (2006), que considera parênteses como uma breve suspensão do tópico discursivo, sem que se constitua uma nova centração tópica. Já para Neves (2012, p. 145), o parêntese mostra-se "atravessando-se em algum ponto do desenvolvimento do tópico discursivo e criando um desvio desse tópico por alguns instantes [...]". Assim, o termo parentético é utilizado no sentido de que o verbo passa de intraoracional (encaixador) para extraoracional, visto que deixa de fazer parte da oração principal.

Schneider (2007), em um trabalho focado em verbos modais, delineia as principais características sintáticas, semânticas e pragmáticas dos parentéticos: i) o fato de terem seu próprio contorno entoacional, comportando-se, portanto, como uma pequena sentença; ii) a falta de um vínculo sintático expresso por algum conector; iii) a relação pragmática que mantém com a oração "hospedeira"; iv) a interrupção prosódica que causa na sentença "hospedeira" e v) a função interpessoal fortemente presente. Como tal, seu uso, invariavelmente, apresenta-se ligado a uma afirmação do falante sobre um fato que é, para ele, verdadeiro, permitindo, por outro lado, que ele se comprometa totalmente. É o que se observa em (11) e (12):

(11) Dentre as pensativas circunstantes, calculo eu, não haverá uma só, que, da sua varanda, não tenha muita vez festejado, a sorrir de inconsciente admiração, a hora do despertar no céu e na terra. (18:Barbosa:Obras)

(12) Eu gostei muito do Marcello como pessoa. Ele é admirável, compreensivo, profundamente humano, inteligente, perspicaz e sensível. E há outra coisa, calculo eu: ele é o anti-herói. Ele nunca foi o herói. Eu também sou assim, um anti-herói. Nunca gostei dessa coisa. (190r:Pt:Intrv:Jrnl) 
v. $8(2)$

401-418

mai/ago 2018
Por meio das ocorrências (11) e (12), é possível notar que o verbo atua de maneira bem diversa de seu uso típico como encaixador. Entre ele e a oração encaixada deixa de haver o complementalizador que, o que reforça o seu comportamento assemelhado a advérbio modalizador epistêmico, assim como assinala Traugott (2012) para o tratamento do I think do inglês.

Em (11), percebe-se que calculo eu é capaz de modalizar o conteúdo proposicional, revelando-se como item que recai sobre quem fala, não sobre os objetos-de-mundo que vinham sendo usados. O mesmo ocorre em (12), pois, quando o falante diz "E há outra coisa, ele é o anti-herói", nota-se que calculo apenas suspende a afirmação que se segue, sendo ela retomada a seguir.

As ocorrências (11) e (12), exemplares de parentetização, deixam evidente também a abstratização, devido à distância que se observa da experiência cognitiva de origem.

Em (13), ao dizer: "o dela, pelo que agora me contam, normativo", percebe-se que apenas ocorre uma breve suspensão da oração, pois o uso parentético de cálculo funciona como uma ressalva que tem o potencial de relativizar o conteúdo afirmado, revelando qual é a natureza da postura epistêmica do falante nesse caso:

(13) Amadrinhei-lha também por procuração, visto cada uma de nós ter breve seguido o seu caminho. O meu, evasivo, de pouco interesse. O dela, calculo, pelo que agora me contam, normativo. (19:Fic:Pt:Lisboa:Pouco)

Segundo Traugott (1989), os parentéticos epistêmicos vão além da subjetividade, pois o falante não está comprometido apenas com a verdade epistêmica, mas com a codificação do ouvinte, por sugerir a esse último a imagem sobre o falante que ele deve fazer (TRAUGOTT, 2012, p. 19). Mais do que significar "essa é minha opinião", valor pragmático que revela subjetividade, o uso de calculo, em casos assim, significa também "não imagine que estou sendo taxativo". Tal fato comprova a intersubjetivização, que está relacionada ao quanto o falante se preocupa com a interpretação do ouvinte, lançando mão do parêntese para gerenciar as expectativas que se instauram na comunicação, como se pode ver em (14): 
(14) Disfarçadamente, tenta observá-la, mas o director literário já tomou a palavra, Imagino que sabe por que o mandámos chamar, calculo. O senhor director tinha querido ser ele próprio a tratar deste assunto, mas um problema urgente surgido à última hora obrigou-o a ausentar-se. (19:Fic:Pt:Saramago:Historia)

O trânsito de calcular ${ }_{1}$ até calcular ${ }_{4}$ elucida a atuação de dois mecanismos que são de suma importância para compreensão do processo de mudança semântica: bleaching e abstratização (HEINE et al., 1991). O primeiro mecanismo envolve absorção de traços, ocasionando um desbotamento dos traços de origem, como foi mostrado nas ocorrências em (9), (10), (11) e (12), em que o verbo calcular, sobretudo quando parentetizado, não faz referência ao ato de computar, mas permite opinar, apresentar ressalvas, se posicionar diante de algo. A abstratização, por sua vez, motiva a generalização de significados, observada por meio da redução das propriedades mais específicas da forma fonte, o que resulta em aumento de contextos de uso.

Neste sentido, pode-se depreender que, com a parentetização, calcular experimenta a proeminência dos traços ligados à subjetividade, ou seja, a expressão modal epistêmica. Alguns traços da forma fonte são preservados e outros neutralizados, e, neste percurso, o uso subsequente tem atributos que se aproximam do conceito expresso no uso anterior e atributos que se particularizam. No caso de calcular, quando já parentetizado, esvazia-se o significado de operação relacionada a quantidades, mas, na forma calculo (eu), reserva-se a ideia algo que se deu pelas faculdades mentais do falante. Isto é, não se trata mais de um raciocínio matemático, mas ainda há resquícios de uma atividade mental que, por meio de instrumentos indutivos ou dedutivos, fundamenta a gênese de uma opinião.

Por meio do quadro 1, possibilita-se a visualização de um panorama das ocorrências com o verbo calcular entre os séculos XIX, $\mathrm{XX}$, e XXI, tanto em seu uso prototípico, quanto em configuração parentética: 
V. $8(2)$

401-418

mai/ago 2018
Quadro 1 - Frequência dos usos do verbo calcular

\begin{tabular}{|c|c|c|c|}
\cline { 2 - 4 } \multicolumn{1}{c|}{} & \multicolumn{3}{c|}{ Usos do verbo calcular } \\
\cline { 2 - 4 } \multicolumn{1}{c|}{} & século XIX & século XX & século XXI \\
\hline prototípico & 11 & 27 & 460 \\
\hline parentético & 2 & 8 & 62 \\
\hline
\end{tabular}

Fonte: elaborado pelas autoras.

Observa-se que, no século XIX, foram encontradas 11 ocorrências de calculo em seu uso prototípico, e apenas 2 ocorrências em configuração parentética. No século XX, foram identificadas 27 ocorrências no uso prototípico, e 8 no uso parentetizado, já no século XXI, o número de usos prototípicos de calculo totalizaram 460 ocorrências, e, na forma parentetizada, 62 ocorrências.

Conforme Traugott (2012, p. 18), em itens como esse, pode-se dizer que se instala um equilíbrio entre o que é internamente orientado (orientado para o falante) e externamente orientado (para o ouvinte).

A multifuncionalidade de calcular, pautada nas diferentes intensidades de seus traços semânticos, propicia a existência de duas atuações: como verbo pleno e dotado de argumentos específicos ou não e outro mais "inovador", como partícula que se assemelha a um advérbio modal. Em números, esses usos parentetizados se sistematizam da seguinte forma: no século XIX, com 2 ocorrências; no século XX, com 8 ocorrências e no século XXI, com 62 ocorrências.

Note-se o aumento da frequência no gráfico abaixo:

Gráfico 1 - Frequência de usos da parentetização do verbo calcular

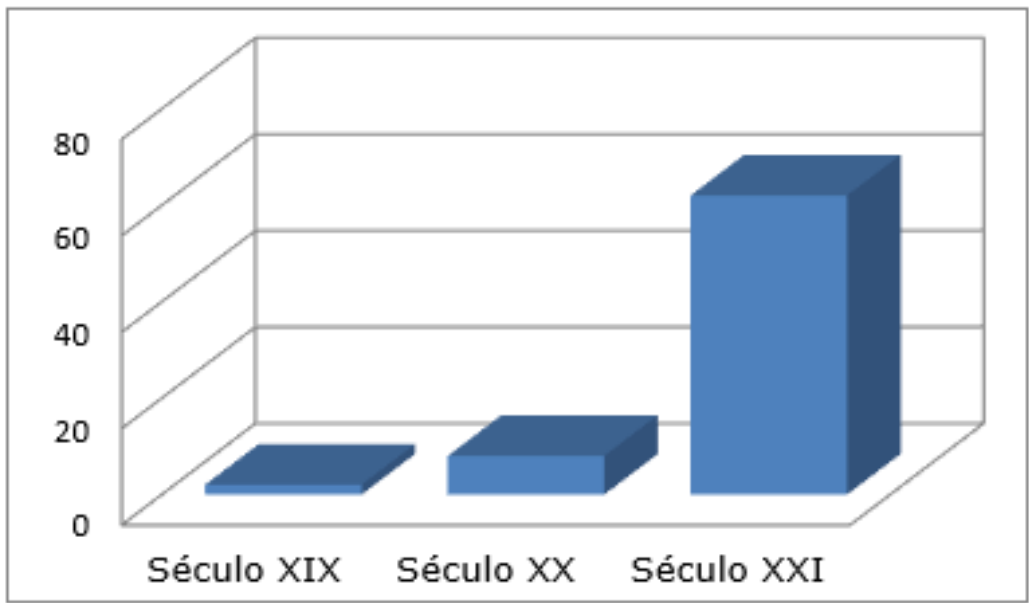

Fonte: elaborado pelas autoras. 
Pode-se observar que o verbo calcular, em sua forma parentetizada, vem se difundindo mais no século atual, sendo utilizado em mais contextos e tipologias textuais. A difusão do uso parentético é observada em romances e em muitos dados orais, o que se notou pelas entrevistas encontradas no Corpus do Português. No século XXI, foram encontradas inúmeras ocorrências do verbo calcular parentetizado em comentários feitos por internautas em diversos blogs, o que ocorre via analogização a outros verbos, como acreditar e crer, que são bastante típicos da expressão de subjetividade e crença do falante.

Aliadas, as transformações semânticas, as possibilidades de atuação pragmática e a descategorialização, isto é, a perda das propriedades identificadoras de verbo pleno indicam a GR de calcular quando parentetizado. Um arranjo possível para seus usos pode ser sistematizado da seguinte forma:

Calcular $1_{\text {quantificador de entes numéricos }}>$ calcular 2 quantificador de entes gerais $>$ calcular 3 (parêntese)sinalizador de postura epistêmica do falante $>$ calcular 4 (parêntese) sinalizador de relação intersubjetiva

Reconhece-se, por meio do arranjo de usos, que sua atuação não pressupõe o encerramento de um sentido para o início de outro, mas a sobreposição de significados. Além disso, assume-se que a parentetização é um recurso que salienta os traços ligados ao posicionamento do falante, observados nos usos 3 e 4, mas não é a única configuração sintática em que o verbo calcular pode revelar traços distantes da quantificação matemática. Entendemos, assim como Fortilli (2015), que a configuração parentética torna mais marcada a necessidade do falante de assinalar sua certeza diante do conteúdo proposicional, acrescentando que a configuração parentética destaca a imagem que o falante quer que o ouvinte faça acerca das suas asserções.

Por meio dos dados encontrados, foi possível observar que o verbo calcular, embora ainda ligado ao eixo da cognição, representando um processo de quantificação e raciocínio numérico, tem-se enveredado para o eixo da modalidade epistêmica, bem como para o âmbito da relação de falante e ouvinte, em um plano interpessoal.

\section{Considerações finais}

É possível apontar empregos diversos para calcular, dois deles baseados em seu sentido de quantificação e operação numérica e outros 
V. $8(2)$

401-418

mai/ago 2018

dois mais distanciados deste, condição que, num primeiro momento, chama a atenção para sua polissemia.

Entre os dois primeiros usos, nota-se a perda de uma restrição de seleção de argumento do verbo, já que o A2, que, em princípio, deveria expressar um termo contável, passa a poder contar com outros traços, pois o falante emprega o calcular para expressar qualquer dedução própria, o que aponta para um processo de generalização de significado do verbo. A tendência de dados mais concretos darem origem a significações mais abstratas cumpre-se aí.

Já com relação aos outros usos, percebe-se mais fortemente um enfraquecimento da especificidade semântica, já que o verbo se desvia ainda mais da concepção de experiência com números e se aproxima do eixo do provável, do possível, do certo ou incerto, ou seja, do campo das modalidades. Assim, tomando por escopo a (in)certeza do falante diante da proposição, calculo torna-se expressivo também da relação entre falante e ouvinte, pois deixa entrever a imagem que o falante gostaria que o ouvinte fizesse sobre sua posição quanto ao que é dito, revelando, desse modo, um processo intersubjetivo.

Ao tomarmos, uma concepção mais abrangente de gramaticalização, não só como mudança de categoria, mas também como a sujeição de um termo a mudanças funcionais específicas, é possível pensar o caso de calcular como um caso alinhado a esse fenômeno. Os quatro usos desse elemento desvelam um trajeto pautado em mudanças semântico-pragmáticas que, reunidas, levam-no de verbo pleno a partícula modal com comportamento semelhante ao dos advérbios.

\section{Referências}

BECHARA, E. Lições de português pela análise sintática. 19. ed. Rio de Janeiro: Nova Fronteira, 2014.

BYBEE, J. Language, usage and cognition. Cambridge: Cambridge University Press, 2010.

CANÇADO, M. Posições argumentais e propriedades semânticas. DELTA, São Paulo, v. 21, n. 1, p. 23-56, 2005.

CASSEB-GALVÃO, V. A atuação de mecanismos desencadeadores de processos de gramaticalização. SCRIPTA, Belo Horizonte, v. 4, n. 7, p.44-59, $2^{\circ}$ sem. 2000.

DAVIES, M.; FERREIRA, M. Corpus do Português: 45 milhões de palavras, 1300s-1900s, 2006. Disponível online em http://www.corpusdoportugues.org. 
FERREIRA, A. B. H. O mini dicionário da língua portuguesa. $4^{\mathrm{a}}$ edição revista e ampliada do mini dicionário Aurélio. $7^{a}$ impressão - Rio de Janeiro, 2002.

FORTILLI, S. C. Parentetização de verbos de atividade mental no português falado e escrito. In: SIMPÓSIO NACIONAL DE ESTUDOS FILOLÓGICOS E LINGUÍstiCOS, 7., 2015, Campo Grande. Revista Philologus. Suplemento Anais..., 2015. p. 110.

GONÇALVES, S. C. L.; LIMA-HERNANDES, M. C.; CASSEB-GALVÃO, V. (org.). Introdução à gramaticalização: princípios teóricos e aplicação. São Paulo: Parábola Editorial, 2007.

HEINE, B.; CLAUDI, U.; HUNNEMEYER, F. Grammaticalization: a conceptual framework. Chicago: University of Chicago, 1991.

HIMMELMANN, N. Lexicalization and grammaticization: Opposite or orthogonal? In: BISANG, W.; HIMMELMANN, N; WIEMER, B. (Eds.). What makes Grammaticalization? Berlin: De Gruyter Mouton, 2004, p. 21-42.

HOPPER, P.; TRAUGOTT, E. Grammaticalization. Cambridge, UK: Cambridge University Press, 1993.

JUBRAN, C. C. A. S Parentetização. In: JUBRAN, C. C. A., KOCH, I. G. V. (Org.). Gramática do Português Culto Falado no Brasil: Construção do texto falado. 1ed. Campinas: Editora da UNICAMP, 2006, v. I, p. 301-357.

LAKOFF, G.; JOHNSON, M. Metaphors We Live By. Chicago: Chicago University Press, 1980.

LAKOFF, G; JOHNSON, M. Metaphors We live by. 2. ed. Chicago: University of Chicago Press, 2002.

MARTELOTTA, M. E. Unidirecionalidade na gramaticalização. In: VITRAL, L.; COELHO, S. (org). Estudos de Processos de Gramaticalização em Português: metodologias e aplicações. Campinas: Mercado de Letras, 2010.

MATOS, M. A. D. N. Verbos polissêmicos: propriedades semânticas e processos metafóricos. 2006. 128f. Dissertação (Mestrado em Linguística) - Faculdade de Letras, Universidade Federal de Minas Gerais, Belo Horizonte, 2006.

MICHAELIS. Dicionário escolar língua portuguesa. São Paulo: Melhoramentos, 2008.

NEVES, M. H. de M. A polissemia dos verbos modais. Ou: falando de ambiguidades. Alfa, São Paulo, v. 44, p. 115-145, 2000.

NEVES, M. H. de M. Texto e Gramática. São Paulo: Contexto, 2006.

NEVES, M. H. de M. A gramática passada a limpo: conceitos, análises e parâmetros. São Paulo: Parábola Editorial, 2012.

SCHNEIDER, S. Reduced Parenthetical clauses as mitigators. A corpus study of spoken French, Italian and Spanish. Amsterdam: John Benjamin Publishing Company, 2007. 
V. 8 (2) 401-418 mai/ago 2018

SWEETSER, E. From etymology to pragmatics. Cambridge: Cambridge University Press, 1990.

TAYLOR, J. Linguistic categorization: prototypes in linguistic theory. Oxford: Oxford University Press, 1989.

TRAUGOTT, E. C. On the rise of epistemic meanings in English: an example of subjectification in semantic change. Language, v. 65, n. 1, mar. 1989, p. 3155 .

TRAUGOTT, E. C. Intersubjetification and clause periphery. English Text Constructions, v. 5 (1), p. 7-28, 2012.

VOTRE,

M. E.<smiles>[AlH]</smiles>
CEZÁRIO, M. Gramaticalização. MARTELOTTA, Janeiro: Faculdade de Letras da Universidade Federal do Rio de Janeiro, 2004. 